\title{
Learning disability and contraceptive decision-making
}

\author{
Sam Rowlands
}

Honorary Associate Professor, Institute of Clinical Education, Warwick Medical School, University of Warwick, Coventry, UK

\section{Correspondence to}

Dr Sam Rowlands, Institute of Clinical Education, Warwick Medical School, Gibbet Hill Campus, University of Warwick, Coventry CV4 7AL, UK; sam.rowlands@warwick.ac.uk

Received 9 January 2011 Accepted 18 February 2011

\section{Introduction}

There have recently been major changes in the law relating to adults who lack capacity to give consent and most textbooks are now out of date on this subject. Many readers will have undergone local training on the implementation of the Mental Capacity Act (MCA) 2005, but this may well have been rather general. [The MCA 2005 can be accessed at http:// www.legislation.gov.uk.] This is therefore the time for an up-to-date assessment of the law in this area. This article is not a complete evaluation of the MCA. It does not cover aspects of fluctuating capacity, lasting power of attorney or advance decisions. Its purpose is to raise awareness on this subject for those working in everyday practice in community sexual and reproductive health care, focusing on women with learning disability.

\section{Learning disability}

Learning disability is the significantly reduced ability of a person to understand new or complex information and to learn new skills, with a reduced ability to cope independently and a lasting effect on development. ${ }^{1}$ The condition starts before adulthood and is permanent. In terms of function, adults with learning disability will score lower than two standard deviations below the mean on a validated test of general cognitive functioning. ${ }^{2}$ Learning disability has a spectrum from mild and moderate through to severe and profound. It does not include less disabling problems encompassed by the term 'learning difficulties' such as dyslexia.

\section{Human rights}

Women with learning disability have the same human rights as those with normal intellectual ability. The following extracts from the internationally agreed International Planned Parenthood

\section{Key message points}

The Mental Capacity Act 2005 has formalised existing case law and added new requirements in respect of decisionmaking by people aged 16 years and over who lack capacity to consent.

A person must be presumed to be competent unless it is demonstrated otherwise. Competence relates to a specific decision and not to all decisions.

- Serious decisions affecting personal welfare matters, including health, are dealt with by the Court of Protection.

The Court of Protection may appoint a deputy to act on behalf of a person who lacks capacity.

- If sterilisation or abortion are being considered as possible options for a person who is considered to lack capacity, and the person has no-one else to support or represent them, an Independent Mental Capacity Advocate must be appointed.

-When assessing a person's capacity to make decisions about contraception, the court will not take into consideration the individual's understanding of what caring for a child involves.

Federation Declaration on sexual rights $(2008)^{3}$ are particularly relevant:

- All persons have the right to be free from violence, including all forms of physical, verbal, psychological or economic abuse, sexual harassment or sexual violence, rape and any other forms of coerced sex within or outside marriage. [Article 3]

- All persons have the right not to be subjected to arbitrary interference with their privacy, family, home, papers or correspondence and the right to privacy which is essential to the exercise of sexual autonomy. [Article 4]

- All persons have the right to be recognised before the law and to sexual freedom, which encompasses the opportunity for individuals to have control and decide freely on matters related to sexuality, to choose their sexual partners .... [Article 5]

- All persons shall have access to community-, school- and health service providerbased information regarding sexuality in understandable language, including the means to ensure sexual and reproductive health and decision-making on when, how, and with whom to have sex and when sexual behaviour will become reproductive. [Article 8] 
- All persons have the right to choose whether or not to marry, whether or not to found and plan a family, when to have children and to decide the number and spacing or their children freely and responsibly .... [Article 9]

Conflicts arise with the sexual partner of a woman with learning disability if there is lack of respect for autonomy, or coercion or violence. Conflicts arise with regard to children born to a woman with learning disability in the event of parental neglect or abuse. Children's law entitles a child to safety and protection from harm, if necessary invoking safeguarding procedures $^{4}$ and fostering. An increasing number of people with learning disability are having children. ${ }^{5}$ Parental IQ is not itself a predictor of parenting performance, but many parents with a learning disability lose their parenting rights.

\section{Contraception for people with learning disability} Community contraception services have for many years assisted those with learning disability as well as other vulnerable adults. Many of these services have developed domiciliary or outreach services, so that these clients do not necessarily have to attend clinics. However, there is a paucity of written documentation on how best these services should be run. ${ }^{6}$ Despite the availability of such services, the majority of contraceptive consultations take place in general practice. Few women with learning disability know about community contraception clinic services, which is regrettable as their staff generally have more time for consultations, and adequate time is crucial for maximising decision-making capacities. ${ }^{7}$

Many women with learning disability feel that they do not have the opportunity to make their own family planning decisions ${ }^{7}$; this applies to starting contraceptive use, duration of use and deciding to discontinue. They often feel that decisions are imposed on them by others.

It is important that the woman should not have the choice of contraception made for her, but that she is allowed the time to make her own choice. The available options are the same as for anyone else. ${ }^{8}$ She will need accessible information about contraception, ${ }^{9}$ not the standard Family Planning Association leaflets, which require a reading age of 13 years. Some women with learning disability can learn to be reliable pilltakers, but experience of contraceptive use by teenagers with learning disability showed pills to have the lowest satisfaction rating, at least according to their mothers. ${ }^{10}$ General practitioners (GPs) have expressed concern that women with learning disabilities would not be reliable users of the pill. ${ }^{11}$

With contraception, as with other areas of life for people with learning disability, a balance needs to be found between protection and empowerment. ${ }^{7}$ Longacting reversible contraception (LARC) methods may be appropriate for some, but effort needs to be put into enabling women with learning disability to exercise as much choice and control as possible.

It is therefore important to consider the sexual partner of the client, if they have one. Often, those with learning disability meet others with learning disability through their joint accommodation or the centres that they attend. It may be that the partner with the milder disability can assist the other in compliance with any repetitive action needed. The concept of time will be absent for most people with learning disability, apart from those with the mildest forms, and support will be required. LARC may be used to avoid the need for adherence. Where there is a trusting relationship without power imbalance, the partner should be involved as much as possible in education and instruction.

Sterilisation remains the most controversial aspect of contraceptive care for people with learning disability. It should only be considered for those women who are physically capable of procreation, who are likely to engage in sexual activity and where there is a real risk of pregnancy. ${ }^{12}$ According to psychologists, sterilisation would not appear to be justifiable in the following circumstances $^{12}$ :

- Risk of being sexually abused - the woman needs protection from the abuse

- Risk of being traumatised by the experience of pregnancy and childbirth

- Perceived lack of parenting ability.

However, a population-based study in Belgium has shown a higher prevalence of sterilisation among women with learning disability than in the general population. ${ }^{13}$ It would be expected that with greater availability of reversible alternatives, sterilisation would nowadays be becoming less common for women with learning disability, as it is in the general population. ${ }^{14}$

Bearing these concerns in mind, Table 1 has been compiled to show common contraceptive methods ranked in order of increasing restrictiveness of a person's rights and freedom of action. In advising people with learning disability, their partners and their carers, such concerns need to be balanced against the perceived importance of the need to avoid unplanned pregnancy.

\section{Mental capacity}

Mental capacity is defined as the ability to make decisions or take actions for oneself. The essence of a test of mental capacity is whether the person concerned enjoys the necessary understanding to embark on the particular enterprise in question. ${ }^{15} \mathrm{~A}$ person is unable to make a decision if they cannot do one or more of the following:

- Understand the information given to them that is relevant to the decision

- Retain that information long enough to be able to make the decision 
Table 1 Methods of contraception in order of increasing restrictiveness of a person's rights and freedom of action

\begin{tabular}{|c|c|c|c|c|c|c|c|}
\hline Method & $\begin{array}{l}\text { Discontinuation } \\
\text { possible by } \\
\text { client }\end{array}$ & $\begin{array}{l}\text { Potential } \\
\text { hormonal } \\
\text { side effects }\end{array}$ & $\begin{array}{l}\text { Effect on } \\
\text { menstruation }\end{array}$ & $\begin{array}{l}\text { Duration } \\
\text { of action }\end{array}$ & $\begin{array}{l}\text { Formal } \\
\text { procedure } \\
\text { necessary } \\
\text { for initiation }\end{array}$ & $\begin{array}{l}\text { Risks of } \\
\text { procedure }\end{array}$ & $\begin{array}{l}\text { Further } \\
\text { procedures } \\
\text { needed for } \\
\text { continuation }\end{array}$ \\
\hline Condom & Yes & No & None & Transient & No & NA & NA \\
\hline Combined pill & Yes & Yes & Improved & Transient & No & NA & NA \\
\hline $\begin{array}{l}\text { Progestogen-only } \\
\text { pill }\end{array}$ & Yes & Yes & Variable & Transient & No & NA & NA \\
\hline Injectable & Yes & Yes & Usually abolished & 12 weeks* & Minor & $\begin{array}{l}\text { None - transient } \\
\text { discomfort from } \\
\text { injection }\end{array}$ & As for initiation \\
\hline Implant & No & Yes & $\begin{array}{l}\text { Often induces } \\
\text { unscheduled } \\
\text { bleeding }\end{array}$ & 3 years & Yes $^{\dagger}$ & Minor & Yes $^{\dagger}$ \\
\hline Intrauterine system & No & $\begin{array}{l}\text { Occasional - mild } \\
\text { and only initially }\end{array}$ & Usually abolished & 5 years & Yes $^{\dagger}$ & Minor & Yes $^{\dagger}$ \\
\hline Intrauterine device & No & No & May worsen & 10 years & Yes $^{\dagger}$ & Minor & Yes $^{\dagger}$ \\
\hline Sterilisation & No & No & None & Permanent & Yes $^{\dagger}$ & $\begin{array}{l}\text { Major (when } \\
\text { compared to } \\
\text { reversible methods) }\end{array}$ & No \\
\hline
\end{tabular}

* Plus potential delay in return of fertility of up to 1 year.

${ }^{\dagger}$ In all but mild cases of learning disability this will usually necessitate general anaesthesia.

NA, not applicable.

- Use or weigh up the information as part of the decisionmaking process

- Communicate their decision - for example, this could be by speech or by using sign language.

In legal terms a person who is deemed to have capacity to consent is referred to as competent and a person who lacks such capacity is termed incompetent.

A person who lacks capacity is defined as a person who does not have the capacity to make a particular decision or to take a particular action for themselves at the time the decision or action needs to be taken. An individual's ability to make decisions is governed by the MCA 2005 in England and Wales, the Adults with Incapacity (Scotland) Act 2000 in Scotland and in Northern Ireland there is currently no primary legislation. This article in written from England, so details will be given of relevant English law.

\section{Decision-making by incompetent adults}

Until the MCA became fully effective in October 2007, decision making by incompetent adults was governed by case law. ${ }^{16}$ The MCA largely incorporates previous case law principles. ${ }^{15}$ The Act only applies to those aged 16 years and over. The Act makes it clear that a person should be presumed to be competent unless it is demonstrated otherwise. The Act also specifies that competence is decision-specific. For instance, a person may be thought to be competent to make a decision about spending money on some furniture, but not competent to consent to a medical procedure. There are some actions enshrined in law that cannot be consented to on behalf of an incompetent person. These include sexual intercourse, marriage, divorce and placing a child for adoption. ${ }^{17}$

\section{Essential procedures to be followed}

Decisions must be made on what is in the person's best interests. The care provider must, so far as is reasonably practical, permit and encourage the person to participate, or to improve their ability to participate, as fully as possible in any act done for them and any decision affecting them. The information relevant to the decision includes information about the reasonably foreseeable consequences of (1) deciding one way or the other or (2) failing to make the decision. Those supporting a person who may lack capacity should not use excessive persuasion or undue pressure. Professionals must consider the views of anyone engaged in caring for the person or who is interested in their welfare.

For people with learning disability, the information presented to them may need to be as simplified language or by the use of visual aids such as pictures, objects or electronic media. ${ }^{18}$ Communication needs to be at a slow pace and may have to be repeated. Support during this process may be needed from a person with whom they are familiar or from an interpreter.

When considering the decision about to be made, regard must be given to whether there is an alternative option that promotes the person's best interests and which would be less restrictive of the person's rights and freedom of action. This originates from cases such as $S L v S L$ in which it was held in the Court of Appeal that insertion of a levonorgestrel-releasing intrauterine system would be a more appropriate intervention 
than sterilisation or hysterectomy for a 29-year-old with severe learning disability and heavy menstrual bleeding, whose mother was concerned that she might become pregnant. ${ }^{19}$ In a more recent case, P's mother wanted P to be sterilised when her second child was delivered by Caesarean section. ${ }^{20}$ However, the judge did not have enough evidence at hand for the court to make a decision on P's competence and best interests, so the Caesarean went ahead without concurrent sterilisation.

Under the MCA a person is not to be treated as unable to make a decision merely because it is an unwise decision. The views of family members may be taken into account as long as it appears that they have the person's best interests at heart.

Restraint of a person who lacks capacity is only permitted if the person using it reasonably believes that it is necessary to prevent harm to the person concerned. The restraint used must be a proportionate response to the likelihood and seriousness of the harm.

\section{Serious medical treatment}

The MCA created the role of Independent Mental Capacity Advocates (IMCAs), to be appointed by National Health Service (NHS) health trusts. Under Section 37 of the MCA, if it is proposed to provide 'serious medical treatment' then, for those who have no-one else to support them (other than paid staff), an IMCA must be appointed to represent the person, unless the treatment is required urgently. 'Serious' medical treatment is defined in secondary legislation ${ }^{21}$ as treatment that involves providing, withdrawing or withholding treatment in circumstances where:

- A single treatment is being proposed and there is a fine balance between its benefits to the patient and the burdens and risks it is likely to entail for them

- There is a choice of treatments and a decision as to which one to use is finely balanced

- What is proposed would be likely to involve serious consequences for the patient.

Serious medical treatment is considered to include sterilisation and abortion. ${ }^{17}$ In practice, most people with learning disability will have family members or friends who take an interest in their welfare and through them will receive support and representation. But IMCAs act as a safeguard for those who do not and they have the right to see relevant medical records.

\section{Code of practice and best interests}

Detailed guidance on mental capacity can be found in the MCA 2005 Code of Practice. ${ }^{17}$ The Act imposes a duty on health professionals to have regard to the Code. The Code is not law, but carers and professionals are expected to give good reasons if they have departed from it. Failure to comply with the Code has no sanctions attached to it, but it can be used in evidence in a court. Health professionals are required to demonstrate in their record-keeping that any decision made has been based on all available evidence and has taken into account any conflicting views. ${ }^{22}$

The following need to be recorded:

- How the decision about the person's best interests was reached

- What the reasons for reaching the decision were

- Who was consulted to help work out best interests

- What particular factors were taken into account.

\section{Best Interests meetings}

A formal Best Interests meeting may be required to decide upon and plan actions needed where the issues facing a particular client are complex. The procedure and the recording of what took place in the meeting must be able to withstand subsequent scrutiny by regulatory bodies or the Court of Protection.

\section{The Court of Protection}

The Court of Protection deals with serious decisions affecting personal welfare matters, including health, previously dealt with by the High Court. ${ }^{17}$ Since 2007 it has had wider powers under the MCA. The court is invariably involved when Social Services, the person with learning disability and the partner of this individual have potentially conflicting views. Social Services have a responsibility to protect the individual from harm in the form of abuse, unwanted sexual intercourse and unwanted pregnancy. They must also protect any children born. However, the individual and her partner need to have their human rights and autonomy respected.

Circumstances in which the court would expect to be consulted include cases involving the proposed sterilisation of a person who lacks the capacity to consent to this or all other cases where there is a doubt or dispute about whether a particular treatment will be in a person's best interests. However, neither sterilisation that is incidental to the management of the detrimental effects of menstruation, nor abortion, need automatically be referred to the court if there is no doubt that this is the most appropriate therapeutic response. ${ }^{22}$ For instance, a woman who is chronically anaemic from large fibroids that have not been amenable to treatment by less radical measures could have a hysterectomy without a prior court hearing.

An application can be made to the court in respect of any person who lacks capacity. The duty officer of the Official Solicitor will advise on the appropriate procedure (http://www.courtfunds.gov.uk/os/adult.htm). The court can make a ruling as to the lawfulness of any act concerning the individual.

Even though the MCA has subsumed relevant case law, the Court of Protection can develop its own case law. In the first case of its kind, the court was asked to consider whether a young married woman lacked capacity to decide whether to use contraception and whether 
it would be in her best interests to be required to receive it. ${ }^{23}$ A local authority applied to the Court of Protection seeking declarations that Ms A lacked such capacity. It submitted that Ms A would need to understand the reasonably foreseeable consequences of the decision: these would include what would be involved in caring for a child if the decision was not to use contraception. The Official Solicitor, on behalf of Ms A, submitted that this would 'set the bar too high' and would deny capacity to large numbers of women who would currently be regarded as having capacity in relation to contraception. The judge, Mr Justice Bodey, came up with a new test for capacity to decide on contraception. He stated that the test would need "to be applied daily in surgeries and family planning clinics, during appointments lasting perhaps less than half an hour".

The judgment was that allowing the use of a wide test that included the social consequences of not using contraception would blur the line between capacity and best interests. It would invoke considerations of whether Ms A could bring up a child, which might then tempt her advisers and carers into treating a decision not to use contraception as unwise, and so not in her best interests. The judge ruled that her understanding of what bringing up a child would entail or the likelihood of the child being removed from her care should not be included in the test. To apply the wider test "would risk a move away from personal autonomy in the direction of social engineering". The test should include only the immediate medical issues surrounding contraception including:

- The reason for contraception and what it does (which includes the likelihood of pregnancy if it is not used during sexual intercourse)

- The types available and how each is used

- The advantages and disadvantages of each type

- The possible side effects of each and how they can be dealt with

- How easily each type can be changed

- The generally accepted effectiveness of each.

When the judge applied the proposed test to this case, he found that Ms A lacked capacity to decide whether or not to use contraception. This was because of the presence of coercive pressure from her husband, both intentional and subconscious. Because there was ongoing work with professionals taking place, the judge made no order at that time about best interests. If this case comes back to court, it will be interesting to see a judgment on the second part of the local authority's application. So far, there is no case law on whether and in what circumstances a woman can be forced to use contraception.

\section{Court-appointed deputies}

Sometimes, the Court of Protection will not make a single judgment but will appoint a person to act for and make decisions for the person who lacks capacity. ${ }^{17}$ This person may be a family member, a friend, a professional working in the local authority or a solicitor. Deputies must act in accordance with the Code of Practice.

\section{Discussion of cases}

\section{Case 1}

Case 1: Ms A is 29 years old. She has moderate learning disability. She has had two previous pregnancies after unsatisfactory relationships with different men and both infants were removed at birth after detailed social work assessments. Two years ago, Ms A married a man with milder learning disability. Since the marriage, there have been reports of obstruction of Ms A's attendance at college and lack of cooperation with her medical and social care by the husband. The husband dominates the relationship and there are reports of domestic violence. It appears that he is keen on having a family. Ms A had previously accepted depot contraceptive injections but did not continue these because of side effects. She has now declined to restart the injections without the husband's knowledge.

Case 1 is the Court of Protection case mentioned above. The history clearly demonstrates Ms A's vulnerability and her inability to fend off the advances of various men. She was consistently assessed as being unable to care for both her infants when living alone. Now, in a stable relationship, she is receiving the benefit of support from her husband who has greater intellectual ability than she has. Nevertheless, she is also being exploited and abused by her husband. She is dominated by him and is disadvantaged in the decisions they make together. She tends to defer to him and fears retribution if she disagrees with him. It is not clear how much she wants another baby, or how much this is her husband's wish. It is interesting that she is judged by the court as lacking capacity to make a decision about use of contraception, not because of her inherent learning disability, but because of an emotional reaction to pressure from her husband. One tends to think of intellectual function in learning disability as constant, but this case demonstrates that this may not always be so.

\section{Case 2}

Case 2: Ms B is 36 years old. She has moderate to severe learning disability. For the last 12 years she has been cohabiting with a man who is sometimes violent towards her. She is dependent on him and her support worker for her care and welfare. The couple has three children. At times these children have lived within the family unit; currently they are all fostered due to varying degrees of neglect. Her partner demonstrates a lack of motivation to use contraception and even prevents health professionals from providing supplies or discontinues the method. Since the birth of her last child, Ms B has consistently expressed a wish not to have any more children. Three years ago Ms B had a subdermal contraceptive implant inserted under general anaesthesia. She is due for a removal/reinsertion but both she and her partner are resisting having the procedure done.

The situation in Case 2 is very different in that Ms B has experienced children living in the family home and does not want further children. Also, she is much less independent than Ms A. She needs daily support from Social Services. She is incapable of looking after herself, let alone any children. Her partner does not look 
after the children either. There is the continuing threat of domestic violence too. Ms B has a complete lack of understanding of the concept of contraception as well as an inability to use it.

Ms B clearly lacks capacity to make decisions about contraception for herself. Her partner is obstructive and uncooperative with health and social care professionals. The Court of Protection would need to make a judgment about Ms B's best interests. Would it be justifiable for her to receive injections with restraint? In the likely event that she could not tolerate or cooperate with a procedure such as implant insertion or intrauterine device/system insertion, would general anaesthesia be justifiable? How would more minor procedures needing to be repeated be compared to female sterilisation in terms of risks and benefits? Female sterilisation is inherently more risky but is a 'one-off' procedure.

\section{Conclusions}

Since the MCA came into force, there have been many referrals of difficult cases to the Court of Protection. Some of these have been high profile, attracting media coverage. These court cases deliberate on the woman's capacity and best interests in great detail. The court has demonstrated that it will not be bounced into fasttrack decisions, for instance when a woman is scheduled for a Caesarean section, and that the parents of the woman do not always get the decision they are asking for. In a significant shift in public policy, the court is now extremely reluctant to order that a sterilisation be performed.

Assisting people who lack capacity to make healthrelated decisions is complex and time consuming. The law dictates that certain procedures are gone through with any individual before decisions are made about contraceptive options. Multidisciplinary work is needed between social workers, members of the Community Learning Disability Team, the GP and specialists in community sexual and reproductive health care. In specific circumstances the case must be placed before the Court of Protection for a ruling. The best interests of the person with learning disability are always paramount.

All this is challenging for the health and social care professionals concerned, who will be involved in lengthy attendance at meetings, report writing and possibly attending court. Those with learning disability invariably receive legal aid for their case to be heard (http://www.legalservices.gov.uk/about_legal_aid.asp). Some cases are heard over several days and may involve more than one hearing. The NHS is undergoing reorganisation and is currently subject to serious national financial strictures. Nevertheless, there is a legal obligation for those involved to contribute to decisions about an individual's capacity and best interests.

Competing interests None.
Provenance and peer review Commissioned; externally peer reviewed.

\section{References}

1 Department of Health. Valuing People: A New Strategy for Learning Disability for the 21st Century. London, UK: Department of Health, 2001.

2 Emerson E, Heslop P. A Working Definition of Learning Disabilities. Stockton on Tees, UK: Learning Difficulties Observatory, 2010.

3 Panel on Sexual Rights. Sexual Rights: An IPPF Declaration. London, UK: International Planned Parenthood Federation, 2008. http://www.ippfwhr.org/sites/default/files/files/ SexualRightsIPPFdeclaration.pdf [accessed 4 December 2010].

4 Anonymous. Working Together to Safeguard Children: A Guide to Inter-Agency Working to Safeguard and Promote the Welfare of Children. London, UK: Department for Education, 2010.

5 Leaviss J, Ewins W, Kitson D, et al. Inclusive Support for Parents with a Learning Disability. London, UK: MENCAP, 2011.

6 Taylor G, Pearson J, Cook H. Family planning for women with learning disabilities. Nurs Times 1998;94:60-61.

7 McCarthy M. Contraception and women with intellectual disabilities. J Appl Res Intellect Disabil 2009;22:363-369.

8 Cooper E. Couples with learning disabilities. In: Killick S (ed.), Contraception in Practice. London, UK: Martin Dunitz 2000;229-240.

9 McCarthy M. 'I have the jab so I can't be blamed for getting pregnant': contraception and women with learning disabilities. Womens Stud Int Forum 2009;32:198-208.

10 Chamberlain A, Rauh J, Passer A, et al. Issues in fertility control for mentally retarded female adolescents: I. Sexual activity, sexual abuse, and contraception. Pediatrics 1984;73:445-450.

11 McCarthy M. Exercising choice and control - women with learning disabilities and contraception. Br J Learn Disabil 2010;38:293-302.

12 Howard R, Hendy S. The sterilisation of women with learning disabilities - some points for consideration. Br J Dev Disabil 2004;50:133-141.

13 Servais L, Leach R, Jacques D, et al. Sterilisation of intellectually disabled women. Eur Psychiatry 2004;19:428-432.

14 Finoulst M, Amy JJ. Female sterilisation is becoming less popular. Eur J Contracept Reprod Health Care 2010;15: 385-388.

15 Brazier M, Cave E. Medicine, Patients and the Law (4th edn). London, UK: Penguin 2007.

16 Herring J. Medical Law and Ethics (2nd edn). Oxford, UK: OUP, 2008.

17 The Stationery Office. Mental Capacity Act 2005 Code of Practice. 2007. http://www.publicguardian.gov.uk/mca/code-ofpractice.htm [accessed 4 December 2010].

18 Family Planning Association. All About Us (CD-ROM). London, UK: FPA, 2008.

19 S (Adult Patient: Sterilisation: Patient's Best Interests), Re [2001] Fam 15.

20 Taylor J. Mother asks judge to force her daughter to be sterilised. The Independent, 16 February 2011.

21 The Mental Capacity Act 2005 (Independent Mental Capacity Advocates) (General) Regulations 2006 (No. 1832).

22 Department of Health. Reference Guide to Consent for Examination or Treatment (2nd edn). London, UK: Department of Health, 2009.

23 A Local Authority v A [2010] EWHC 1549 (Fam). 